\title{
EL VÍA CRUCIS DE UNA CENICIENTA
}

\author{
Eugenio Murillo Fuentes
}

\begin{abstract}
RESUMEN
Las herramientas de la sociocrítica permiten rastrear la memoria subterránea de muchas manifestaciones culturales; incluso aquellas que son producto de las artes visuales. Las cubiertas de los libros se ubican dentro de ese rango.

En el presente artículo analizamos la correspondencia entre la obra literaria La loca Prado, del escritor costarricense Virgilio Mora y la cubierta del libro que la contiene; ilustrada con una obra pictórica del artista Miguel Hernández.
\end{abstract}

\begin{abstract}
The tools of social criticism enable us to tree the memory underlying many cultural manifestations, including those resulting from the visual arts. Book covers are part of this category. This article is an analysis of the correspondence between the literary work $\mathrm{La}$ loca Prado, by the Costa Rican author Virgilio Mora, and its book cover, illustrated with a picture by the artist Miguel Hernández.
\end{abstract}

"Mejor morir de pie, que vivir de rodillas"

Dolores Ibarruri

\section{Preliminares}

En un enfoque sociocrítico de los productos culturales, la función de los aparatos ideológicos que los administran es parte esencial de los efectos que deben ser identificados e interpretados en el receptor-consumidor de esos productos.

El presente artículo aborda los contenidos culturales del "empaque" con que la novela La loca prado, de Virgilio A. Mora, se ha presentado al público en su primera edición (Mora 1998). Se trata entonces de un análisis de la cubierta del libro (Fig. 1) que se hará un poco al margen de cierto aparato crítico (titulogía, paratextos, etc.) y más al arbitrio de los códigos 


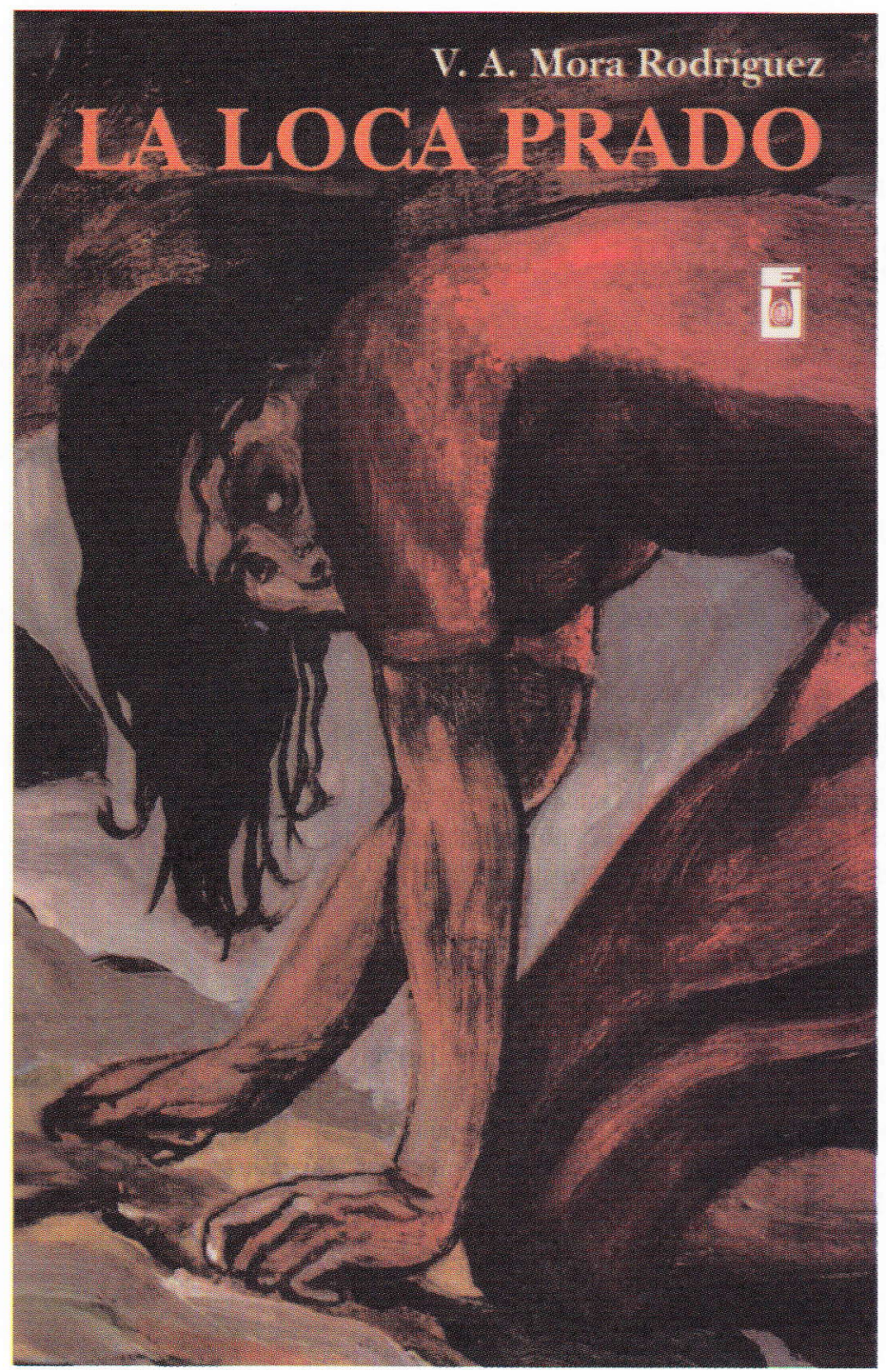

Fig. 1. Cubierta del libro "La Loca Prado" culturales implícitos que funcionan como interpretantes dialógicos entre un material plástico y otro verbal al cual trata de traducir. Por tanto, es importante señalar que el término "intertexto" lo usamos también referido a "intertextos visuales" relacionados con imágenes.

Nuestro trabajo no inicia, como es usual, con una sinopsis del libro. En su lugar, hemos preferido incorporar en el transcurso de nuestro ensayo, y en relación con los temas que tratamos, algunas citas que recogen "el alma" del relato $y$, para no llenar el texto de notas repetitivas, desde este momento advertimos que todos los destacados en cursiva en las citas de la novela en cuestión son nuestros y, además, nos referiremos a la primera edición de 1998, por lo que sólo señalaremos el número de página correspondiente al final de cada cita.

\section{La cubierta del libro. Generalidades}

Se trata de una edición de bolsillo, de pequeño formato: $13.5 \mathrm{cms}$. de base x $21 \mathrm{cms}$. de altura. La cubierta se compone de elementos tipográficos y de una ilustración que sirve de soporte a la totalidad.

Todos los elementos tipográficos se ubican en la parte superior del campo visual:

a. En el ángulo superior derecho, el nombre del autor de la obra (V. A. Mora Rodríguez), escrito con mayúsculas y minúsculas, en letras blancas de 18 puntos (Times-Bold). 
b. Inmediatamente debajo, el título de la obra LA LOCA PRADO, escrito sólo con mayúsculas, en letras de color naranja de 40 puntos (Times-Bold).

c. Debajo del título, y también alineado a la derecha, un pequeño logotipo de la Editorial de la Universidad de Costa Rica en color blanco.

Después de los mencionados elementos tipográficos tenemos la ilustración, piedra angular de nuestro análisis. La información visual de esta ilustración la hemos desglosado en cuatro partes:

1. Los elementos; 2. la figura; 3 . el color; 4. la composición

\section{La ilustración}

\subsection{Los elementos}

En principio, se trata de la dimensión más simple. La ilustración ofrece sólo un elemento claramente reconocible: la figura de una mujer. Otro elemento sería su entorno, el cual es bastante impreciso. Podemos hablar de "un suelo" sobre el que está apoyada y de un fondo. Se trata más de "percepciones" espaciales que de elementos figurativos concretos.

\subsection{La figura}

La figura es el centro de atención de la cubierta. Como lo hemos observado, se trata del único elemento reconocible. La mujer "es" la cubierta, por lo que está en estrecha relación con el título del libro. La asociación es inmediata y para el espectador no existe la menor duda de que esa mujer es "la loca Prado" (o viceversa). La figura ocupa la mayor parte del campo visual y su dimensión excede al formato, puesto que queda cortada una sección de su cuerpo. No obstante, la sección visible permite una perfecta reconstrucción de la totalidad de la figura, cuya postura se presenta como la principal fuente para nuestra propuesta interpretativa.

\subsubsection{La postura}

La ilustración muestra a una mujer vista de lado, reclinada en el suelo y apoyada sobre sus rodillas y su mano y brazo izquierdos. Con su mano y su brazo derechos, la mujer realiza alguna cosa, un simple movimiento, o algún trabajo. Su cuerpo está encorvado hacia adelante. La figura está dirigida hacia el lado izquierdo del campo visual, por lo que queda incompleta en el lado derecho. La cara de la mujer mira, por encima de su hombro, al espectador.

El primer "intertexto" visual con la imagen nos refirió al cuento para niños La Cenicienta, del escritor francés Charles Perrault (1628-1703). Dicho cuento relata la historia de una niña huérfana que era maltratada por su madrastra y despreciada por las hijas de ésta. Cargando con su cruel destino, le toca servir a sus amas y callar sus dolores. Es usual que en los libros de cuentos la figura de la "Cenicienta" sea representada en posición reclinada, sobre el suelo, fregando el piso, posición muy similar a la de nuestro personaje. (Figs. 2 y 3: ilustraciones de libros infantiles, del cuento La Cenicienta.) 

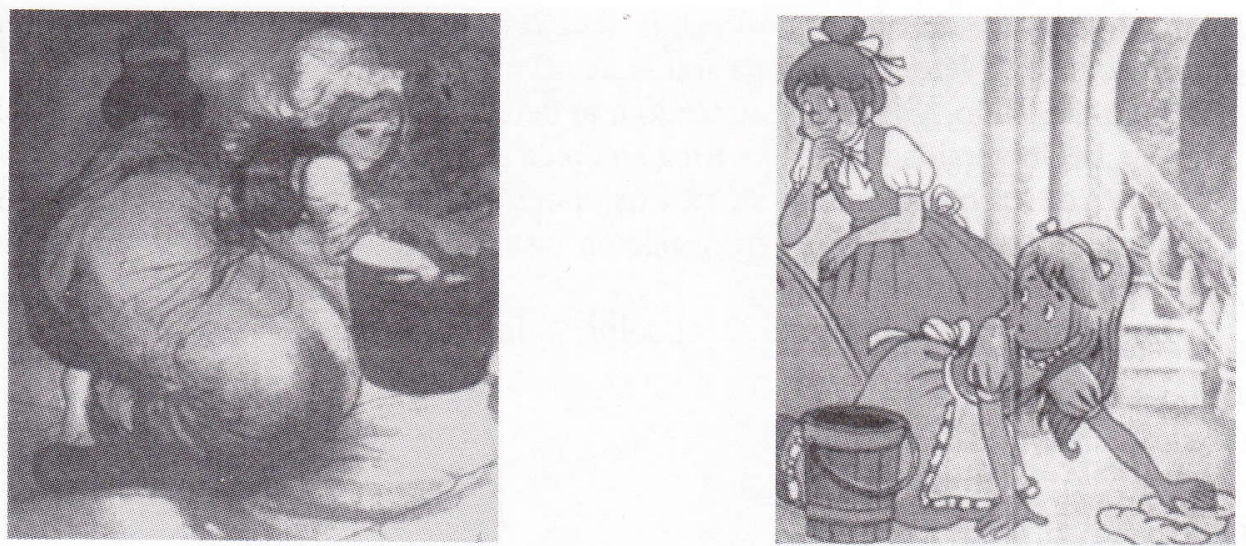

\section{Figs. 2 y 3. Ilustraciones de libros infantiles, del cuento La Cenicienta.}

Al igual que María (el personaje protagónico de la novela), la Cenicienta es una sirvienta huérfana. En la siguiente cita, Luisa, la hija de María, conversa con su muñeca Meche:

...mamá y yo no tenemos ni un lugar para que nos entierren, nada y no hay esperanza, lavando y aplanchando ropa ajena,... (13).

Aquí es directamente la voz de María:

...como si en este pueblo no fuera suficiente para ser mala, el ser cocinera, pobre, huérfana y el no haber terminado ni la escuela primaria...

O bien, cuando una cliente se refiere a María:

Así son todas las sirvientas, no agradecen nada (35).

La posición (reclinada, de rodillas en el suelo), y la postura (encorvada, con la cabeza baja) presentes en esa imagen "cenicienta" de La loca Prado, nos remiten a una interesante serie de otros intertextos, como veremos.

\subsubsection{La posición de la humildad y de la devoción}

Los términos arrodillado y reclinado, en nuestro país y en nuestra cultura, nos ponen de inmediato en contacto con el discurso cristiano, específicamente el católico. La Iglesia Católica, en distintos momentos de sus rituales, requiere que sus fieles se arrodillen y las bancas de las iglesias católicas están concebidas como "reclinatorios"; es decir, ofrecen un nivel elevado en su parte anterior para que los fieles se arrodillen y puedan orar y participar de las rutinas con cierta "comodidad". La posición de rodillas es, por definición, incómoda y hasta torturante. Se ofrece como posición para la expiación de culpas. Los fieles que confiesan sus 
pecados en el confesionario deben hacerlo de rodillas, pues en la tradición católica esta posición figura como la mayor manifestación de humildad y de devoción. (Fig. 4. "San Francisco arrodillado". Pintura del pintor español Francisco de Zurbarán (1598-1664)). Es así como algunos fieles llegan incluso a desplazarse de rodillas no sólo dentro del recinto de la iglesia sino también fuera de él, a lo largo de grandes distancias como en el caso de las romerías, con la correspondiente degradación física que ello implica.

En el discurso visual cristiano tenemos otro ejemplo de gran paralelismo con la imagen y con el contenido del libro que nos ocupa. Se trata del "Vía Crucis". El "Vía Crucis" es el camino que recorre Jesús hacia el Monte Calvario, llevando sobre sus espaldas el madero en el que sería crucificado. Se trata de un camino torturante hacia la muerte física, o bien hacia la eterna vida espiritual. En ese recorrido, Jesús cae al suelo tres veces. Las representaciones visuales de esas caídas tienen un gran paralelismo con la figura que nos ocupa. Compárense la figura $\mathbf{1}$ y la figura $\mathbf{5}$ (Caída de Jesús en su camino al Calvario): la mujer de la cubierta del libro y Jesús yacen de rodillas, con la mano izquierda apoyada al suelo y la derecha ocupada, cabizbajos y apuntando hacia el lado izquierdo del campo visual.

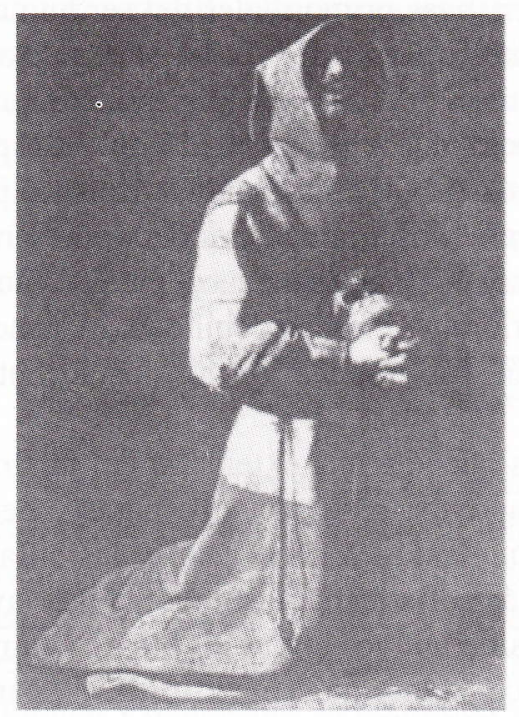

Fig. 4. Pintura de Zurbarán "San Francisco arrodillado"

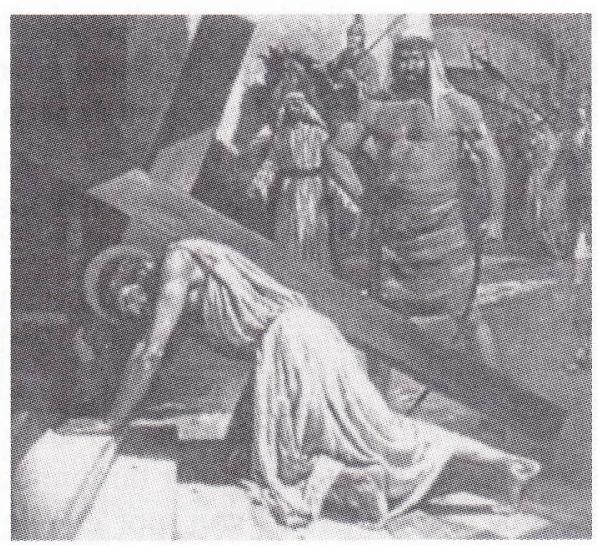

Fig. 5. Caída de Jesús en su camino al Calvario (Ilustrador desconocido).

La palabra "calvario" es usada popularmente para referirse al sufrimiento moral. El concepto "vía crucis" también se ha incorporado al "rumor social" para referirse a períodos muy duros en la vida y a procesos dolorosos y degradantes. El "Vía Crucis" tiene la inexorable carga del destino, se trata de algo que tenía que suceder. La vida de María tiene todos esos elementos, su destino es inexorable y está marcado por la fatalidad:

$$
\text { ...jamás de los jamases, siempre pobres,... (13). }
$$

Desde que tengo uso de razón, mi vida es una desgracia (15). 
En el caso de María, se trata, sin embargo, de un Vía Crucis que no le ofrece ninguna expectativa, mientras que la muerte es el objetivo de Jesús y el futuro se entiende en términos de la vida eterna. En el caso de María, no. Para ella sólo existen presente y pasado, y el pasado es lo único que se rescata:

El ayer no era mejor que el presente pero era algo conocido, un sitio en donde había estado una vez (67).

La siguiente cita también remite al Calvario, a los últimos momentos de Jesús en la cruz, cuando le pregunta al Padre por qué lo ha abandonado:

Entonces me veo tal como soy... una mujer desamparada a la que parece que Dios hubiese olvidado, un ser sin remedio, con la vida marcada antes de nacer (90).

\subsubsection{Hombre vs. animal o cosa}

La posición de rodillas complementada con el apoyo de brazos y manos sobre el suelo (como la ilustración de La loca Prado) es comúnmente conocida como posición “de cuatro patas".

La biología establece como una de las características primordiales del ser humano la facultad de sostenerse erecto en sus dos piernas (Homo Erectus). Esa particularidad lo hace superior al resto de los mamíferos que no gozan de un sentido del equilibrio tan desarrollado. Considerando que el ser humano es el más evolucionado y desarrollado de las especies existentes, esa condición "erecta" es sinónimo de superioridad. La posición "de cuatro patas" en el discurso biológico es, por consiguiente, exclusiva de los animales, es decir, de seres inferiores al hombre. Los bebés, que apenas "gatean", se desplazan de cuatro patas a causa de su imposibilidad de erguirse. Gatear es un estado anterior que implica debilidad, incapacidad, torpeza e inmadurez. "Salir de cuatro patas" de algún sitio implica los mismos atributos de gatear, con el agravante de que se refiere a adultos.

Es interesante observar cómo en los espacios que son una extensión del mismo ser humano, muchos elementos tienen también cuatro apoyos, o sea "cuatro patas". Se trata por lo general de objetos creados por el hombre y que están a su servicio: las sillas, las mesas, las camas, los armarios. En una dimensión más sofisticada, las neveras, las lavadoras y las cocinas pueden tener también cuatro puntos de apoyo, lo que implica "cuatro patas". Las "cuatro patas" son, por consiguiente, una constante de "servidumbre", característica también en muchos animales de carga al servicio del hombre: los caballos, las vacas, los camellos, etc.

Retomando el discurso biológico, "Homo erectus" se refiere a la cualidad humana de poder mantenerse en pie. En la biología, cuanto más se eleva del suelo un mamífero merced de su equilibrio, tanto más evolucionado. La posición "erecta" es un atributo, una condición positiva. Tanto es así que "jorobarse" no sólo se considera anatómicamente perjudicial, sino que demuestra la creciente debilidad como consecuencia de la vejez. Del "rumor social", expresiones referidas a personas tales como "con los pies muy puestos en la tierra", o "como un roble" hacen referencia a la posición erguida, derecha. La primera implica también sensatez y lucidez; nótese que "tener los pies" muy puestos en la tierra descarta automáticamente la posición arrodillada. La segunda también la descarta en tanto los árboles crecen derechos, siempre hacia arri- 
ba. Implica además orgullo y dureza. Por lo general, la expresión de que alguien "es como un roble", se complementa con una segunda parte: "que no se deja doblegar".

En la fisiología de la sexualidad, la condición erecta es interpretada también positivamente. La "erección" del miembro viril es demostración de fuerza, de vitalidad, de salud y, por qué no, de juventud. Se da por oposición a la flacidez, como condición inferior. Tenemos nuevamente el sistema de relaciones:

$$
\begin{aligned}
& \text { "arriba - abajo" } \\
& \text { "positivo - negativo" } \\
& \text { "fuerte - débil" } \\
& \text { "estar de pie - estar de rodillas". }
\end{aligned}
$$

\subsubsection{Un asunto de jerarquía}

En relación con el poder, la posición de rodillas tiene también connotaciones de carácter político y social. Por lo general, el acto de arrodillarse no se da sin una razón concreta; nadie se arrodilla por puro gusto, en parte por lo incómoda que es esa posición. Una persona siempre se arrodilla ante algo o alguien que se supone muy superior y digno de respeto, temor o admiración. En las cortes, los súbditos tenían que arrodillarse ante el rey ("ponerse a sus pies"), y el rey los miraba "en picada" desde lo alto de su trono. Quien está arrodillado se encuentra abajo, en una posición y un nivel inferior. Del discurso religioso, así como del monárquico, deriva la palabra genuflexión, la que implica el acto de adoración mediante la postura arrodillada:

En las numerosas tradiciones antiguas la rodilla es el principal asiento de la fuerza corporal... el símbolo de la autoridad del hombre y de su poder social (Chevalier 1995: 888).

La degradación se da en el momento en que las rodillas se hincan y se apoyan sobre el suelo; es decir, cuando la acción implica "descenso" de nivel; cuando demuestra un acto de vasallaje, humillación o rendimiento. Las expresiones "servir o ponerse de alfombra", "agacharse" o "bajar la cabeza" ante alguien hacen alusión a este tema. Son sinónimo de "sometimiento", de "reducción" y de "subordinación". Quien actúa de tal manera se degrada, se minimiza y demuestra su debilidad y su falta de carácter.

Una prolongación de este sistema de relaciones lo encontramos en la expresión referida a alguien que "es un(a) echado(a) p' atrás". Una persona "echada p' atrás" no sólo se supone erguida, sino también orgullosa y altanera. En ese mismo sentido tenemos otra expresión, la de "salir con la cabeza muy en alto", que implica que alguien salga airoso, victorioso y con el honor salvado de alguna situación. Nuevamente se observa la superioridad frente a la inferioridad de lo que está abajo. Veamos ésta última expresión en comparación con la siguiente cita, la voz de María:

Casi me muero cuando me tuve que tragar la realidad. Nada que hacer. Bajar la cabeza, echar para adelante, agarrarse a una esperanza cada vez más flaca, casi invisible, como una sombra cuando no es de día ni de noche... (75). 


\subsubsection{El dolor y el placer de la perversión}

En el ámbito de la sexualidad, la posición de rodillas o de "cuatro patas" juega un importante papel. La postración es de por sí una constante en la práctica sexual.

Dentro de las prácticas sexuales, la degradación y el sometimiento pueden figurar como estimulantes. El juego voluntario al "déspota" y al "sometido" pueden tener efectos excitantes. En la industria que se ha desarrollado en torno a la sexualidad, se aprovechan y explotan esas prácticas y es así como ha surgido el mundo del "cuero" y se produce toda suerte de objetos y artefactos para prácticas sádicas y masoquistas.

En la práctica sexual de pareja, es inevitable la tendencia a que alguna de las partes "dé la pauta", dirija y mande las acciones. En el marco de ese sistema de relaciones, una de las partes se "ofrece" como objeto de goce sexual del otro, siendo ese ofrecimiento algo que a su vez satisface y excita al oferente. Expresiones como "se le entregó" muestran la alta dosis de "cosificación" de una de las partes. En el mundo de la pornografía, la perversión de esasacciones se lleva a niveles extremos en los que se habla de "esclavos y esclavas" al servicio absoluto de las fantasías de sus amos. El abuso de esos juegos llega a degradar y a calar hondo en el alma humana. Puede así ocurrir que "uno hace de la humillación, del dolor y de la vergüenza, un modo de vida que echa raíces muy hondas" (41).

Las prácticas sexuales retorcidas en que había nacido y crecido Carmelo, el esposo de María en La loca Prado, le conducen de adulto a una deformación de los principios establecidos. Él es consciente y sufre: “... porque soy un pervertido, porque me gusta que me degrade, me encanta que me escupa en la cara, que se orine en mi cuerpo, que me haga sentir como un gusano" (100).

Como lo hemos anotado, parte de lo morboso de algunos juegos sexuales radica en la fingida degradación que se experimenta. Las posiciones de rodillas, o "de cuatro patas" entran en esta categoría. Así, una mujer o un hombre que practica el sexo oral con su pareja, arrodillado frente a ella, presenta un cuadro que mezcla la adoración del discurso religioso, y a la vez, el sometimiento y el vasallaje: una persona hincada, postrada a los pies de la otra, para satisfacerla. La persona que está de pie no ejecuta, sino que deja ejecutar y mira desde lo alto a alguien que se le somete.

La posición "de cuatro patas" tiene connotaciones animales: "El sueño en que me veo haciéndole el amor a mamá como un perro, no cesa" (66). Tiene una fuerte carga de sometimiento, en la medida en que es una posición que deja desprotegido al que la practica. Aquí debemos anotar que el cuerpo tiene un frente y una espalda. Por el frente se ejecutan las acciones: los brazos y las piernas dominan el ámbito frontal, al igual que la cara con todos los sentidos que ésta representa. La espalda, o parte trasera del cuerpo, queda fuera del control del individuo. La expresión "le clavaron un puñal por la espalda", en relación con la traición y la deslealtad, hace referencia a esa vulnerabilidad. El frente y la espalda equivalen también a la "presencia" y la "ausencia" del individuo. En las artes escénicas, los artistas deben evitar en lo posible dirigir al público sus espaldas. Las acciones deben ofrecer los frentes, o los perfiles del elenco. "Darle la espalda" a alguien, o estar "de espaldas al mundo" son expresiones que ponen de manifiesto esa particularidad. Por su parte, el frente o "presencia" del individuo está en estrecha relación con su rostro y muy especialmente con la mirada. "Dar la cara" es enfrentar algo o a alguien. También se habla de "de cara al nuevo siglo", o bien "cara a cara". Estando solo un individuo, la 
espalda, y en un sentido más amplio todo el lado posterior del cuerpo, no sólo se ofrece como recurso para ausentarse, sino también para protegerse. En casos de peligro de accidente de tránsito o aéreo, se recomienda a los individuos envolverse en sí mismos como una forma de compactar el cuerpo; sin embargo, esa posición suele adoptarse instintivamente. Se trata de la posición fetal, la cual ofrece la mágica sensación de que todo ha quedado atrás, de que el exterior quedó en otra parte.

Otro aporte del "rumor social" es la expresión "así murió un chino...", que se completa "...pero murió contento". A pesar de que no logramos dar con su origen, sí logramos comprobar que entre generaciones adultas es entendida uniformemente: se utiliza con morbosidad cuando un varón se coloca inclinado, doblado por la cintura y formando un ángulo con su cuerpo que deja su trasero expuesto, en sitios donde otros circulan. La expresión se refiere al acto sexual por el recto y al "jocoso" peligro que corre el individuo colocado en esa posición (tan expuesta y oferente), de que otro varón lo penetre.

En la relación homosexual que se da entre Juvencio y Carmelo, producto de un proceso de degradación creciente que ambos habían sufrido desde su más temprana infancia, sale a relucir la práctica sexual antes anotada en el siguiente fragmento: "Qué lástima que no puede ver al hijo revolcándose como lo hacía él. Ahora, hincate cabrón...” (100).

$\mathrm{El}$ arte, que a lo largo de la historia ha recogido e inmortalizado las actividades y los fenómenos de la sociedad, nos muestra en infinidad de ejemplos la temática que nos ocupa:

En la figura 6, la pintura "Desnudo inclinado" (1914) del artista autríaco Egon Schiele (1890-1918), muestra la posición "de cuatro patas" en una mujer, en la que se advierte la actitud de "entrega".

La figura 7 muestra una escena del clásico cinematográfico "La dulce vida" (1960), en la que el actor italiano Marcello Mastroianni "cabalga" sobre su compañera. Se trata de una

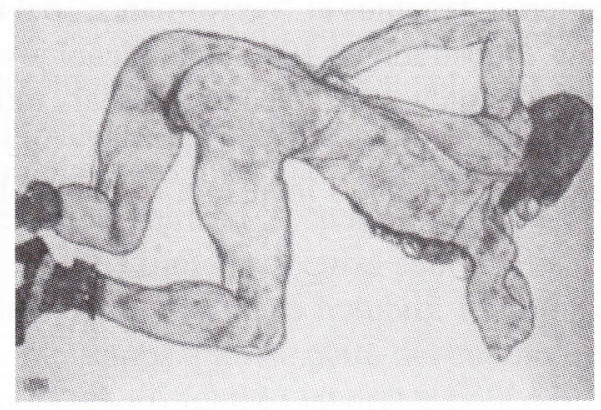

Fig. 6. Egon Schiele.

Desnudo inclinado. 1914. Lápiz, acuarela y pinturas opacas.

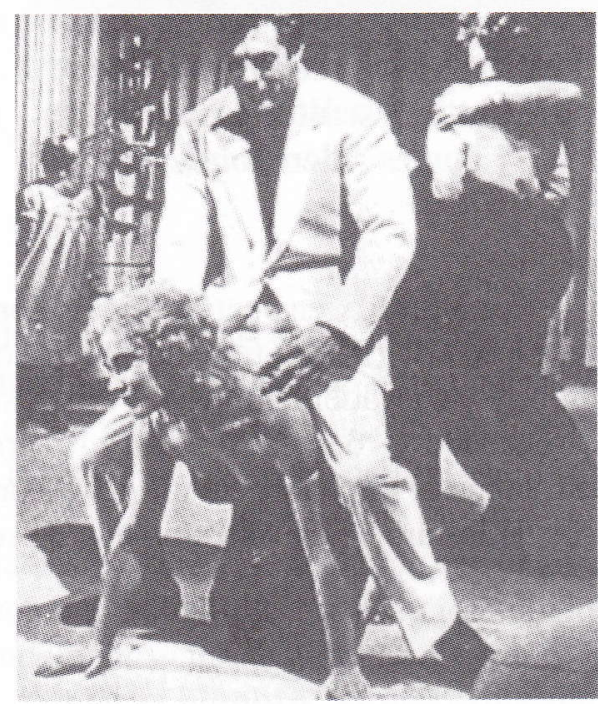

Fig. 7. Escena del clásico cinematográfico "La dulce vida" (1960), en la que el actor italiano Marcello Mastroianni "cabalga" a su compañera. 
fantasía de fuerte acento erótico y además degradante. La mujer es convertida en un animal, al servicio del varón. Observemos además que la espalda del cuerpo humano es equivalente al lomo de los animales; es decir, el sitio en el que se lleva la carga. Aquí encontramos de nuevo expresiones fabricadas que aluden el asunto. Por ejemplo, cuando se dice que alguien "ya no aguanta el peso que lleva sobre sus espaldas", para referirse al exceso de trabajo o responsabilidades. No sólo se alude al trabajo pesado y humilde del campo, donde es usual cargar realmente sobre la espalda o los hombros, lo cual implica un encorvamiento hacia adelante y hacia abajo; también alude a la relación hombre-animal, a la degradación y al vasallaje.

El pintor, escultor e impresor inglés Allen Jones aglutina las distintas variables de la humillación en su obra "Mesa Escultura" (1969) (Fig. 8). Se trata de una mesa; es decir, de un objeto al servicio del hombre. La base es una mujer colocada "de cuatro patas" (implicaciones sexuales degradantes) que además va vestida con la moda del "cuero" (implicaciones sado-masoquistas). Ella tiene la cabeza hacia abajo con su rostro cubierto por el pelo y se mira en un espejo ((mirar hacia abajo = humillación), superficialidad y vanidad (el espejo)). Por otra parte, la mujer carga sobre su espalda la lámina que define la mesa (implicaciones animales y cosificación del género femenino).

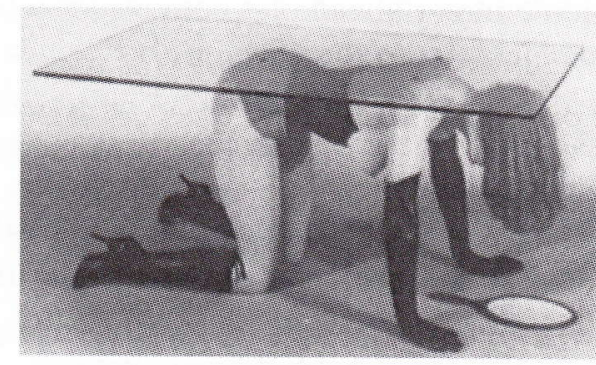

Fig. 8. "Mesa Escultura" (1969) del pintor, escultor e impresor inglés Allen Jones.

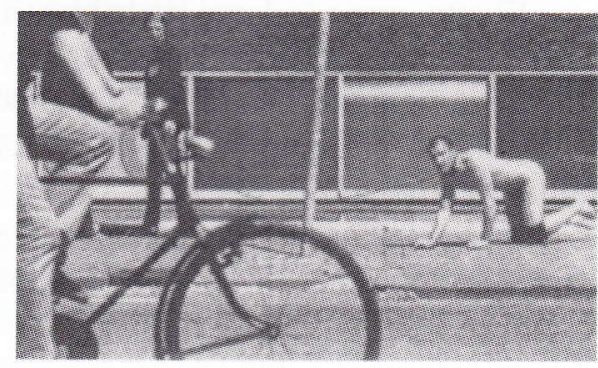

Fig. 9. "El Perro de Pawlow". "Performance" del artista europeo Oleg Kulik, mostrado en 1996 en la bienal "Manifesta", en Rotterdam.

Por último, y en contraposición con la obra anterior, tenemos el "performance" del artista europeo Oleg Kulik titulado "El Perro de Pawlow", mostrado en 1996 en la bienal joven "Manifesta", de Rotterdam. (Fig. 9) El mismo artista se degrada, y es "sacado a pasear" totalmente desnudo y "de cuatro patas". Amarrado a un cordel es conducido por las calles de la ciudad, como si se tratara de un perro europeo cualquiera, llegando incluso a orinar en los troncos de los árboles levantando una de sus piernas.

\subsubsection{Estar por los suelos}

Continuando con el tema de la posición arrodillada, y, en general, con las rodillas, no queremos concluir sin antes tocar otros aspectos relacionados.

Las rodillas salen a relucir también en el tema del miedo. Por ejemplo, es usual la expresión "se me aflojaron las rodillas" en casos de miedo o pánico. La expresión tiene sus- 
tento en la realidad, pues en determinadas situaciones las piernas realmente parece que abandonan a su portador. Los casos de vértigo ilustran muy bien ese fenómeno. El afectado siente que le fallan las piernas (las rodillas) y teme desplomarse. La incapacidad de las piernas, o sea de las rodillas, representa entonces debilidad y vulnerabilidad. Es también el caso de muchos ancianos, cuyas piernas flaquean. Las piernas y las rodillas fuertes y la postura erguida y firme son un distintivo del poder.

En el sistema de relaciones erguido - arrodillado (equivalente a arriba - abajo) está presente el discurso del bien y del mal: el cielo, lo bueno, la divinidad y lo elevado = arriba. El infierno, lo malo, lo demoníaco y lo pedestre $=$ abajo.

En las relaciones de poder, los pies deben tenerse sobre el suelo, nunca las rodillas. Es decir, se debe estar erguido o sentado. La posición erguida implica la lucha; la de sentado, el poder reposado del "trono". Es así como se explican frases como "pisotear" o "ponerle la pata" a alguien. En el discurso visual católico también aparece ese símbolo: el arcángel que oprime al diablo bajo su pie, o bien, la virgen que aplasta con su pie a la serpiente. La expresión acerca de "una persona muy plantada" alude el tema de varias maneras: una planta (vegetal), cuyas raíces la mantienen firme sobre el suelo y le facilita su crecimiento (desarrollo, ascención). Las "plantas" de los pies, sobre el suelo, representan firmeza y realismo. Alguien "muy plantado" es, en consecuencia, decidido, firme, resuelto y fuerte. No fue ese el caso de la agobiada María:

Ahora es el pasado el que no me deja vivir como yo quisiera, no me permite pararme con mis pies en este día... (42).

La posición de rodillas ha sido utilizada para torturar. Antiguamente, a los niños que "no daban la talla" en la escuela se les exigía ponerse de rodillas por largos períodos de tiempo, en un determinado lugar del aula y frente a una pared. Esa práctica degradante era a veces complementada con granos de maíz sobre el suelo, para intensificar el suplicio. Igualmente es conocida esa posición en círculos penales y en los regímenes dictatoriales.

\subsection{La expresión}

Para concluir nuestro análisis de la figura de la mujer de la cubierta del libro, haremos unas anotaciones en relación con su rostro. En primer lugar, la mirada que figura como "el espejo del alma" se trata de una mirada extraviada que refleja la demencia. Sus pupilas no son paralelas y su rostro no enfrenta a su observador. Hay en ese gesto una actitud esquiva y temerosa, al mirar sólo "por el rabillo del ojo".

La timidez, y quizá sobre todo el temor y la desconfianza, se acentúan con el gesto de mirar por detrás de su hombro. El hombro actúa como escudo protector de la infamia humana. Pensemos que esa parte del cuerpo tiene una importante gama de significaciones. El hombro es, en un sentido laboral o bélico, un soporte. "Meter el hombro" es una expresión que alude ese papel. La carga se suele llevar sobre los hombros. Las "hombreras" eran parte importante en las armaduras, protegían los hombros y ampliaban la capacidad de lucha de los guerreros en los combates "cuerpo a cuerpo" y en los que se recomendaba atacar de costado. Los trajes de vestir masculinos han portado siempre hombreras, las cuales exaltan el cuerpo 
en tanto ensanchan la apariencia de la caja toráxica; es decir, sugieren fuerza, y, por consiguiente, poder. Hoy en día, la ropa femenina casi es inimaginable sin hombreras. Las razones son las mismas.

Otro aspecto relacionado con el rostro y con la expresión es la cabellera. La mujer tiene su melena suelta y desgreñada. Unos mechones caen sobre su cara. Se aprecia en ello el descuido y el abandono de su estado; sobre todo en un contexto cultural en el que las mujeres suelen llevar siempre su cabello arreglado, ya sea por un determinado corte o por accesorios como cintas o prensas. La mujer anda "toda mechuda", lo que, además, se entiende como "añeja" y "cochina"; condiciones que desde la clásica perspectiva clasista (despectiva) son además características de los pobres. María y su hija también eran pobres y, en consecuencia, estigmatizadas: "...en la escuela aprendió que somos los pobres más pobres de todos..." (13).

Sin embargo, la peor de sus pobrezas, la moral, se la impuso la sociedad, el mundo. Para María, eso era el destino: "La vida me jugó otra trastada... La vida" (112). Se invierten así los papeles: en el cristianismo, la muerte representa la vida. Para María, la vida es la muerte en su versión más cruel y despiadada. Su liberación es la locura, la cual viene a ser una "muerte en vida".

\section{El color}

Aquí solo queremos anotar una cierta "suciedad" en la paleta y la utilización del color negro para dar las sombras. Se trata de recursos tenebristas que concuerdan muy bien con lo mórbido del relato.

La misma suciedad de la paleta conduce a un dominio perceptible del color marrón. Ningún color se percibe puro y luminoso. El color marrón (café) es sinónimo de humildad y de pobreza. En el caso de nuestra ilustración, en la que ese color no aparece como tal y sólo lo percibimos en la dimensión sucia de su utilización, la humildad y la pobreza se degradan aún más.

La mujer lleva un traje de color rojo, que tampoco se presenta como color puro. El rojo es característico de los ánimos exaltados. Está asociado a la pasión en su dimensión más animal. La "zona roja" es claro ejemplo de ello. Se asocia con la sexualidad en la medida que las mucosas que intervienen en las prácticas sexuales lucen de color rojo encendido (los labios y toda la parte interna de la boca, también las mucosas genitales).

En el texto, el color rojo se vuelve protagónico cuando Juvencio es sorprendido por Carmelo vestido de mujer:

Juvencio, mi vida. Me doy vuelta y me encuentro con unos labios rojos, brillantes, húmedos, unas cejas repintadas, unas pestañas largas, una mujer más alta que yo, vestida todo de rojo, rojas las zapatillas de tacón alto, roja una estola que llevaba sobre la cabeza, roja la cartera... (86-7).

La cita anterior permite otras interpretaciones. Por ejemplo, que la mujer de la ilustración representa al Carmelo travestido. Desde esa perspectiva, el título del libro también permite otra lectura. La "loca" se referiría no a la condición de demente de María, sino al calificativo despectivo de "loca", que en Costa Rica alude al homosexual afeminado y al travesti. Nosotros, sin embargo, no dividimos las interpretaciones y ofrecemos la posibilidad múltiple que permite aglutinar todos los personajes en una sola representación simbólica. 
Por otra parte, el rojo es el color de la guerra (Marte, el planeta rojo), y, por lo tanto, tiene implícita la violencia y la fuerza desatada. Que "la Loca Prado" aparezca vestida de rojo, envuelta en un traje rojo adherido a su cuerpo, alude a una condición de víctima, tanto de la pasión como de la violencia.

La imagen es, en definitiva, sombría. Sombría como un calabozo o como un rincón abandonado. Como la vida misma de María, o bien de Carmelo.

\section{La composición}

La dirección de la figura es un elemento determinante en la composición de la imagen. La cabeza de la mujer apunta hacia la izquierda del campo visual, en tanto su espalda, hacia la derecha.

En nuestra cultura occidental, donde la escritura implica un movimiento de izquierda a derecha, esa dirección determina importantes condiciones evaluables en términos de lo positivo y de lo negativo. La dirección hacia la derecha es positiva, implica avance y progreso. En su defecto, la dirección hacia la izquierda representa retroceso.

Este sistema de relaciones se ve fortalecido por los conceptos "diestro" y "siniestro". Lo "siniestro" es la excepción, lo sospechoso, lo raro, e incluso lo repudiable. Antiguamente se consideraba un defecto cuando un niño era zurdo. Existían terapias correctivas para tal "aberración" que se transformaban en verdaderas torturas para los afectados. Basta observar la información que da el diccionario para comprender que la palabra prácticamente sólo connotaciones negativas implica: "Izquierdo (lado siniestro). Perverso, mal intencionado. Infeliz, funesto. Que aterra. Propensión a lo malo, vicios o resabios. Daño, destrucción o pérdida." De allí deriva la expresión "levantarse con el pie o por el lado izquierdo" para referirse a un día lleno de mala fortuna.

En la política, 1o "izquierdo" ha estado igualmente estigmatizado. En el tráfico automotor, la derecha es el carril de avance ("Mantenga su derecha"). Los sistemas de señalización de carreteras se apoyan en ese entendido y dan por natural su interpretación sin información textual complementaria (Fig. 10).

De ese modo, la posición de la mujer en la cubierta es también consecuente con el relato. La mutilación de la imagen por el lado derecho del campo visual permite una interpretación adicional en términos de la mutilación moral y social de la loca Prado.
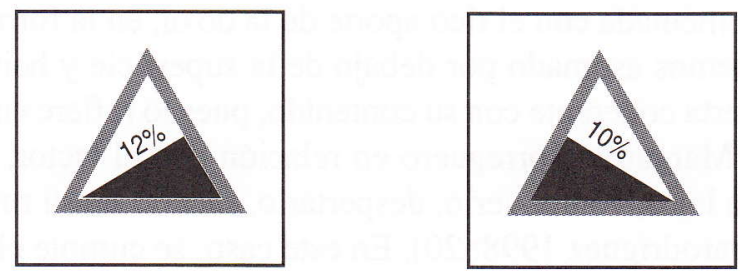

Fig. 10. Señales de tránsito. La primera indica el porcentaje de ascenso; la segunda, el porcentaje de descenso de la carretera. 
Un último factor son los elementos tipográficos de la cubierta. Éstos no son parte de la ilustración, han sido colocados muy posteriormente por el diseñador de la editorial, pero curiosamente son consecuentes con la línea interpretativa que hemos seguido hasta ahora. Obsérvense nuevamente las figuras 5, 6 y 8. En ellas tenemos ejemplos de cómo la espalda puede convertir al ser humano en animal de carga, siendo ese lastre algo que lo degrada y lo aplasta. Ese es el papel que juega el título del libro La loca Prado colocado en la parte superior del campo visual. El texto se convierte en el estigma, en esa carga social que va acabando con María (o Carmelo), que le impide incorporarse y que le reduce a una figura sin nombre que no se logra explicar su sino:

Extraño que pueda hablar de tanto dolor en tan pocas palabras... (111).

\section{A modo de conclusión}

Desde la invención de la imprenta y hasta la fecha, la literatura en su forma tangible, es decir como libro, ocupa un papel determinante en la vida de los seres humanos. En las sociedades modernas, es impensable que la vida de alguien discurra totalmente al margen de estos objetos que a veces llegan a nosotros como un imperativo del espíritu, otras como una obligación académica, o bien como elementos decorativos o de estatus. Para muchas personas es un importante pasatiempo visitar las librerías con el único afán de mirar libros. En las vitrinas y en los anaqueles, la literatura se ofrece al espectador amén de su empaque, con el que se establece un primer contacto visual. La cubierta de un libro, así como su título, son los primeros elementos inductores en la relación lector-libro. El impacto que causen el título y la cubierta en el espectador, determinarán la mecánica de selección imprescindible ante la imposibilidad de ver y hojear todo lo que una librería o biblioteca ofrece. Así, la cubiertas de los libros son referentes de gran importancia que deben anunciar y presentar, consecuentemente, la obra que contienen.

Con base en teorías de la percepción y de las artes visuales en general, hemos hechos un análisis detallado de la cubierta del libro La loca Prado, tomando como punto de partida la imagen que la ilustra y que la sostiene en su totalidad; en este caso, una pintura del artista Miguel Hernández (Costa Rica 1961) que no ha recibido el crédito correspondiente en la edición del libro que nos ocupa. Luego, en el análisis de la figura, hemos precisado su postura, las direcciones y tensiones más importantes dentro del campo visual, así como su expresión. Por último, hemos analizado el color y los aspectos compositivos generales de toda la cubierta, incluidos los elementos tipográficos que la complementan. Se trata de una lectura apoyada en teorías existentes y complementada con el rico aporte de la doxa, en la forma de sus frases hechas y estereotipadas. Nos hemos asomado por debajo de la superficie y hemos podido comprobar que se trata de una cubierta coherente con su contenido, pues lo refiere enigmática y consecuentemente. Y, como dice Margarita Borreguero en relación con el lector, "hay que intrigarlo sí, pero hay que llegar más lejos, conmoverlo, despertarlo, sacarlo de su rutina..." (Prólogo del libro Mano a Mano. Morarodríguez 1998: 20). En este caso, se cumple el objetivo. No sabemos si el artista plástico Miguel Hernández y el diseñador Juan Carlos Fallas son o no conscientes del acierto en su trabajo. Nuestras acciones en cierta medida las controlamos, pero somos portadores de una genética cultural que nos conduce al margen de nuestra voluntad. 


\section{Bibliografía}

Bazin, Germain. 1976. Historia del Arte. De la Prehistoria a nuestros días. Barcelona: Ediciones Omega.

Braun, Gerhard. 1993. Grundlagen der Visuellen Kommunikation. München: Bruckmann.

Chevalier, Jan. 1995. Diccionario de los símbolos. Barcelona: Editorial Herder.

Gaya, Juan A. 1972. Zurbarán. La obra pictórica completa. Barcelona: Editorial Norguer S.A.

Heller, Eva. 1993. Wie Farben Wierken. Hamburgo: Büchergilde Gutenberg.

Mora, Virgilio. 1998. La loca Prado. San José: Editorial de la Universidad de Costa Rica.

Morarodríguez, V.A. / Moro, P. 1998. Mano a mano. San José: Editorial Colección Némesis.

Sabarsky, Serge. 1985. Egon Schiele. Vom Schüler zum Meister. Hamburger Kunsthalle.

1994. Art. Das Kunst Magazin. Hamburgo (12).

1996. Art. Das Kunst Magazin. Hamburgo (8).

Fantasía. Libro de cuentos para niños. España: Ediciones A. Saldaña Ortega.

1978. Fantasía en color. Cuentos para niños. Barcelona: Ediciones Susaeta S. A.

1965. La Sagrada Biblia. Carolina del Norte: C. D. Stampley Enterprices, Inc.

1983. Life im Kino. Alemania: Time-Life Bücher.

1992. Stroke. Revista Gay. 